Report: DOE/ID/14067-1
00120496
C/O Final Reports
U.S. Department of Energy
03/15/2004
(Technical)

\title{
UNIVERSITY REACTOR INSTRUMENTATION PROGRAM
}

\author{
Final Report \\ Fiscal Year 2001 Grant \\ for the \\ University of Florida Training Reactor
}

Submitted by

Dr. William G. Vernetson

Director of Nuclear Facilities

Department of Nuclear and Radiological Engineering

College of Engineering

University of Florida

Gainesville, Florida

March 2004

U.S. Department of Energy

Award \#DE-FG07-01ID14067 


\section{TABLE OF CONTENTS}

1.0 Overview of Grant Usage ....................................................................................... 1

2.0 Summary of 2001B2 URI Grant Usage ................................................................... 3

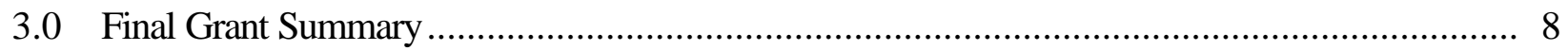

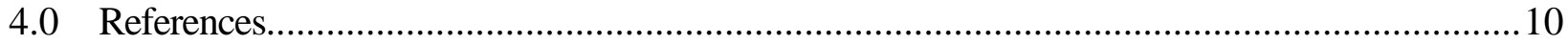

\section{LIST OF TABLES}

Table 1 Total Cost for Proposed UFTR Facility Instrumentation and Equipment Upgrade for 2001B2 Grant Period................................................... 11

Table 2 Financial Results of UFTR 2001B2 University Reactor

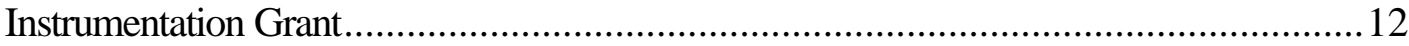




\section{FINAL REPORT ON FISCAL YEAR 2001 \\ UNIVERSITY REACTOR INSTRUMENTATION GRANT \\ TO UNIVERSITY OF FLORIDA TRAINING REACTOR}

\subsection{Overview of Grant Usage}

Recognizing that the U.S. Department of Energy University Reactor Instrumentation Program was developed in response to widespread needs in the academic community for modernization and improvement of research and training reactors at institutions such as the University of Florida, the items proposed to be supported by this grant over its 18-month period had been selected as those most likely to reduce forced outages, to meet regulatory concerns that had been expressed in recent years by Nuclear Regulatory Commission inspectors or to correct other facility problems and limitations. Department of Energy Grant Number DE-FG07-01ID14067 was provided to the University of Florida Training Reactor (UFTR) facility through the University Reactor Instrumentation Program. The original proposal submitted in December 2000 requested support for UFTR facility instrumentation and equipment upgrades for eleven (11) items in the amount of $\$ 123,970$. A breakdown of the items requested and total cost for the proposed UFTR facility instrumentation and equipment improvements is contained in Table 1 synthesized from the proposal submittal.

The items actually supported by the grant allocation in the 2001B2 grant period provided valuable support for the process of modernization and improvement at the University of Florida Training Reactor which, like many such facilities, is over 40 years old. Although several major instrumentation improvements were supported by the University of Florida around 1970 and later, it had been some years since significant funding had been available for reactor facility instrumentation upgrades until the University Reactor Instrumentation (URI) grants began in 1990. Such grants supported UFTR modernization and facility 
upgrades for four grant periods from 1990B91 through 1993B94. Similarly, the renewal of the grants for the 1998B99 period was welcome support. However, by no means did the 1998B99, the 1999-2000, the 2000B2001 or even this 2001B2 grant meet all the clearly identified needs of a facility such as the UFTR, but they have allowed the process to continue. For more details on the grant usage for the 2001B2 period, the reader is referred to Section 2.0.

\subsection{Summary of 2001B2 URI Grant Usage}

For the 2001B2 URI grant period, Department of Energy Grant DE-FG07-01ID14067 was provided to the University of Florida Training Reactor (UFTR) facility through the DOE University Reactor Instrumentation Program. The original proposal submitted in December 2000 requested support for UFTR facility instrumentation and equipment upgrades for eleven (11) items in the amount of $\$ 123,970$ with no cost sharing requested by DOE and no official cost sharing committed by the University of Florida for any of the eleven items. A breakdown of the items requested and total cost for the proposed UFTR facility instrumentation and equipment improvements is contained in Table 1 taken from the proposal submittal. It should be noted that the proposed UFTR facility instrumentation and equipment can generally be subdivided into three categories: (1) to improve reactor operations, (2) to improve existing facility/NAA Laboratory operations, and (3) to expand facility capability. All of these items were selected recognizing the objectives of the University Reactor Instrumentation Program to respond to the widespread needs in the academic reactor community for modernization and improvement of research and training reactor facilities, especially at large and diverse institutions such as the University of Florida. These needs have been particularly pressing at the UFTR which is the only such research and training reactor in the State of Florida which is undergoing rapid growth in a variety of technical areas. 
Although only a portion of the proposal could be funded, four key items were included in this $2001 \mathrm{~B} 2$ URI grant referenced previously. Specifically, this DOE University Reactor Instrumentation Program grant was awarded for $\$ 54,556$ to provide funds toward the purchase of the following needed instrumentation:

1 ADEMCO Vista 20 Security System

2 Nuclear Instrumentation Linear Channel Components

3 Uninterruptible Power Supply

$4 \quad$ Freeze Dryer System (partial funding)

The quoted estimated costs from the December 2000 proposal, the grant allocation costs and actual costs for the items covered under this grant are summarized in Table 2. In addition, total actual costs shown in column 3 of Table 2 are $\$ 1,318.83$ more than was projected in the proposal and $\$ 6,508.83$ more than the grant amounts with the nuclear instrumentation costing quite a bit more $(\$ 11,290.35)$ than proposed (primarily due to price increases and extra necessary components) and the uninterruptible power supply costing quite a bit less $(\$ 3,200)$ due to cost discount. The same is true of the freeze dryer so that actual cost was only slightly more than the allocated total $(\$ 624.48)$ since other facility users able to support part of the acquisition cost were not able to be identified. These values mean that the grant was charged as shown in column 5 with no facility input (cost sharing) committed officially but some values as such are shown in column 6 of Table 2 . The unused portion of the grant at $\$ 3,320$, effectively available, could cover some of the other implementation costs, especially for the neutron detector instrumentation channel components. Clearly, the funding supplied by this grant was well used in obtaining and implementing quality equipment at the best price possible. As with most grant periods, there were significant vendor problems with incorrect price quotes or incorrect designation of the requisition item which only became apparent when attempting to order or upon receipt of an item. 
As indicated in Table 2, the first item is a security system control panel with associated wiring and detectors. The existing system is over 30 years old and has been the subject of repeated maintenance over the past 5 years. Some of its detection devices are no longer replaceable from stock. Modifications made many years ago make troubleshooting some parts of the system such as the backup battery charging subsystem essentially impossible, further increasing maintenance frequency to replace batteries. Currently, various parts of the system cable trays remain open for maintenance access further degrading facility appearance. In light of relicensing plans, this item is also a key consideration for housekeeping appearance considerations. The cost of a replacement ADEMCO Vista 20 security system including turnkey installation by a certified vendor was to be $\$ 2,206$. Replacement of this system was expected to save up to 5 days of maintenance per year, decrease security alarm response and greatly improve facility appearance. Unfortunately, with the advent of the September 11, 2001 terrorist attacks, costs and availability as well as requirements on replacements became much more difficult. The response of the proposed vendor was not optimal with the cost more than doubling as we even extended the grant period in attempting to arrange for this installation. The item was even encumbered at one point for much more than the proposed cost but without turnkey installation as proposed. Unfortunately, the modification documentation was not able to be completed and the cost eventually became prohibitive so this item was not obtained accounting for $\$ 2,206$ of the grant money not being spent.

The second item is a new linear channel including compensated ionization chamber (CIC) plus picoammeter and autoflux controller. In recently replacing a failed uncompensated ion chamber (UIC), degraded connectors had been replaced on the compensated ion chamber but the CIC is very near end-oflife based on tests by the Department of Nuclear and Radiological Engineering electronics engineer. In addition, the picoammeter and autoflux controller have both been the subject of considerable maintenance in 
the last six years with major gain concerns expressed about the picoammeter. Replacing the entire channel including wiring with essentially identical components all at the same time is strongly recommended. The requested components were quoted at a total of $\$ 31,350$ plus $\$ 300$ for wiring/connectors and expected significant staff efforts for implementation. Because of vendor price increases and initial failure to specify minor needed items, the cost of this item as noted in Table 2 was $\$ 42,940.35$ versus $\$ 31,650$ with $\$ 33,111.52$ charged to the grant. The components for this instrumentation channel are now available at the facility so this item has been an excellent though costly acquisition with installation planned during a future refueling (optimal) or if the channel fails beyond repair before that time. The $\$ 42,940.35$ spent on the item assures that the necessary replacement instrumentation is available to assure effective reactor utilization during its relicensing period.

The third item is an uninterruptible power supply (UPS) for use in the analytic laboratory which is an integral part of our reactor facility. Our laboratory PC-based analyzers and high purity germanium and other detector systems as well as other laboratory equipment is frequently expected to operate for long counts and other experiments especially over weekends and holidays. Because of the facility's location and continuing power distribution anomalies and other problems, our detector systems are subjected to repeated cycles due to relatively frequent short power outages and less frequent but equally disturbing lengthy power outages. Therefore, the Department of Nuclear and Radiological Engineering electronics engineer had strongly recommended acquisition of an uninterruptible power system. The requested Tripp Lite UPS is sized to meet our current needs and expected growth over the next several years. The requested UPS was quoted at $\$ 9,500$ but an educational discount plus a price reduction resulted in a $\$ 3,200$ savings for a grant cost of $\$ 6,300$ as this item is currently in the process of being implemented. 
The fourth item funded is the fifth item in Table 1. Listed fourth in Table 2, this item is an improved freeze dryer system with drying chamber and freeze flasks for the analytical laboratory. The current freeze dryer is only five liters and was nearing end-of-life requiring significant and costly maintenance several times in the last two years. In addition, its freezing capacity restricts potential users. Until 2000, we could borrow usage from a freeze dryer in the physics department; however, their new building is now on the other side of campus and prevents significant utilization and allows no control over samples. A number of our research and educational users are interested in mercury levels in their project samples (lake, river and ocean sediments as well as fresh edibles including fish, apples and oranges, and other samples) with a desire that samples be freeze dried. The existing system is frequently unavailable either for maintenance or because of limited throughput. A new larger capacity freeze dryer system would contribute significantly to synergistic throughput enhancement for trace element analysis using neutron activation in the reactor. The cost of this freeze dryer system including freeze dryer, drying chamber and freeze flasks was proposed at $\$ 16,390$ including a university discount but was only partially funded in the grant with $\$ 11,200$ allocated. Unfortunately, the full funding was not provided and efforts to get other contributors were not successful. As a result, the system was obtained as planned without some of its enhancement features at a cost of $\$ 11,824.48$, only slightly above the grant allocation. Unfortunately, dealings with Labconco and Fisher as the two companies involved were difficult with first delivery of a 220 volt system but a 120 volt motor. Subsequently, a system with a failed vacuum pump was delivered. Finally, a working system was delivered at the $\$ 11,824.48$ cost and has been implemented and well used at the NAA Laboratory facility for processing sediment, biological and other samples for various trace element evaluation projects.

In general, all three (3) instrumentation items acquired under the 2001B2 grant are directly related to improving reactor safety, minimizing personnel doses per ALARA commitments, and addressing inspection 
concerns in recent years. With these acquisitions, nuclear instrumentation capabilities for the soon to be relicensed UFTR were significantly upgraded. In addition, having the uninterruptible power supply and the freeze dryer system will greatly facilitate analytical laboratory usage especially for neutron activation of samples irradiated by the reactor, both for educational and research users at all levels as well as occasional service users. Needless to say, all these acquisitions contribute to professional facility operations assuring that the planned HEU-to-LEU conversion and the in-progress relicensing of the facility will occur with a facility in high usage. The only drawback was the inability to obtain the quoted security system due to various circumstances but mostly due to personnel time commitments and complications due to the events of September 11, 2001. The net result of the acquisitions has been improved, more reliable reactor utilization in keeping with grant objectives; this has also meant increased user interest in facility utilization and ability to meet commitments to users.

\subsection{Final Grant Summary}

Overall, the instrumentation and other equipment obtained under the 2001B2 University Reactor Instrumentation Program grant has assured that the goals of the program were well understood and met as well as possible at the level of support provided for the University of Florida Training Reactor facility. Though the grant support of $\$ 54,556$ provided toward the purchase and installation of the proposed instrumentation certainly did not meet many of the facility s needs, the instrumentation items obtained and implemented, or to be implemented, did and will meet some critical needs and hence the goals of the Program to support modernization and improvement of reactor facilities such as the UFTR within the academic community.

Certainly, reduction of forced unavailability of the reactor is the most obvious achievement of the University Reactor Instrumentation Program to date at the UFTR. Nevertheless, the ability to close out 
several expressed inspection concerns of the Nuclear Regulatory Commission with acquisition of linear channel instrumentation this year is also very important. Most importantly, with modest input from facility funds (unexpectedly more this year due to the cost of nuclear instrumentation in item 1), the facility has been able to continue and even accelerate the improvement and modernization of a facility, especially in the Neutron Activation Analysis Laboratory, that is used by nearly every post-secondary school in the State of Florida and several in other states, by many departments within the University of Florida, and by several dozen high schools around the State of Florida on a regular basis each year. Better, more reliable service to such a broad-based user community can only support further growth in quality facility usage.

In the 2001B2 grant period, the University Reactor Instrumentation Program has supported instrumentation and equipment upgrades not only to improve reactor operations but also to improve existing facility/NAA Laboratory operations to support and facilitate reactor utilization. Indeed, one of the significant limitations in usage of the UFTR facility has been the throughput of the NAA Laboratory (NAAL). The fewer personnel and less equipment time used in the NAAL, the more usage of the reactor that can be accommodated and the more users that can be accommodated in the laboratory facility. A number of NAAL improvements have been implemented with facility and University of Florida support including upgrading primary and support software packages for spectral analysis; nevertheless, in addition to the software, several additional improvements in the UFTR facilityғexisting NAA Laboratory capabilities were badly needed to increase productivity to support further expansion of usage, particularly among those intending to learn to use the laboratory facilities themselves. Acquisition and implementation by the URI Program grant of items such as the mixed gamma calibration source and the fluke scopemeter last year, the emergency response kit components, the analog and digital self-reading pocket dosimeters and some of the portable shielding the previous year, and the uninterruptible power supply and the improved freeze dryer 
system this year has significantly increased and improved quality throughput of the reactor and the laboratory facility. The result is more and higher quality reactor operations as well as improved and more reliable results for the NAA Laboratory including as a side benefit several surveillances required by UFTR technical specifications to facilitate the synergistic operations of these facilities.

As newer, more reliable, state-of-the-art instrumentation is implemented at the UFTR facility, the message from the Department of Energy to the broad-based diverse community of academic and other users is that the mission of university reactors such as the University of Florida Training Reactor is regarded as important and should be supported. Since the technically trained and educated cadre produced by facilities such as the UFTR is needed throughout the resurgent nuclear energy industry wherever radiation or radioactivity is used, this message is most important for the technological future of this country. It is sincerely hoped that this University Reactor Instrumentation Program can be continued and its level of funding increased in future years to meet the program stated objective of improving and modernizing operation of university reactors to an even higher degree.

\subsection{References}

W. G. Vernetson, AGrant Application for the University of Florida Training Reactor (UFTR) to the U.S. Department of Energy . . . for the Fiscal Year 2001 University Reactor Instrumentation (URI) Program, @ecember 2000. 
Table 1

\section{TOTAL COST FOR PROPOSED UFTR FACILITY INSTRUMENTATION AND EQUIPMENT UPGRADE FOR 2001B2 GRANT PERIOD}

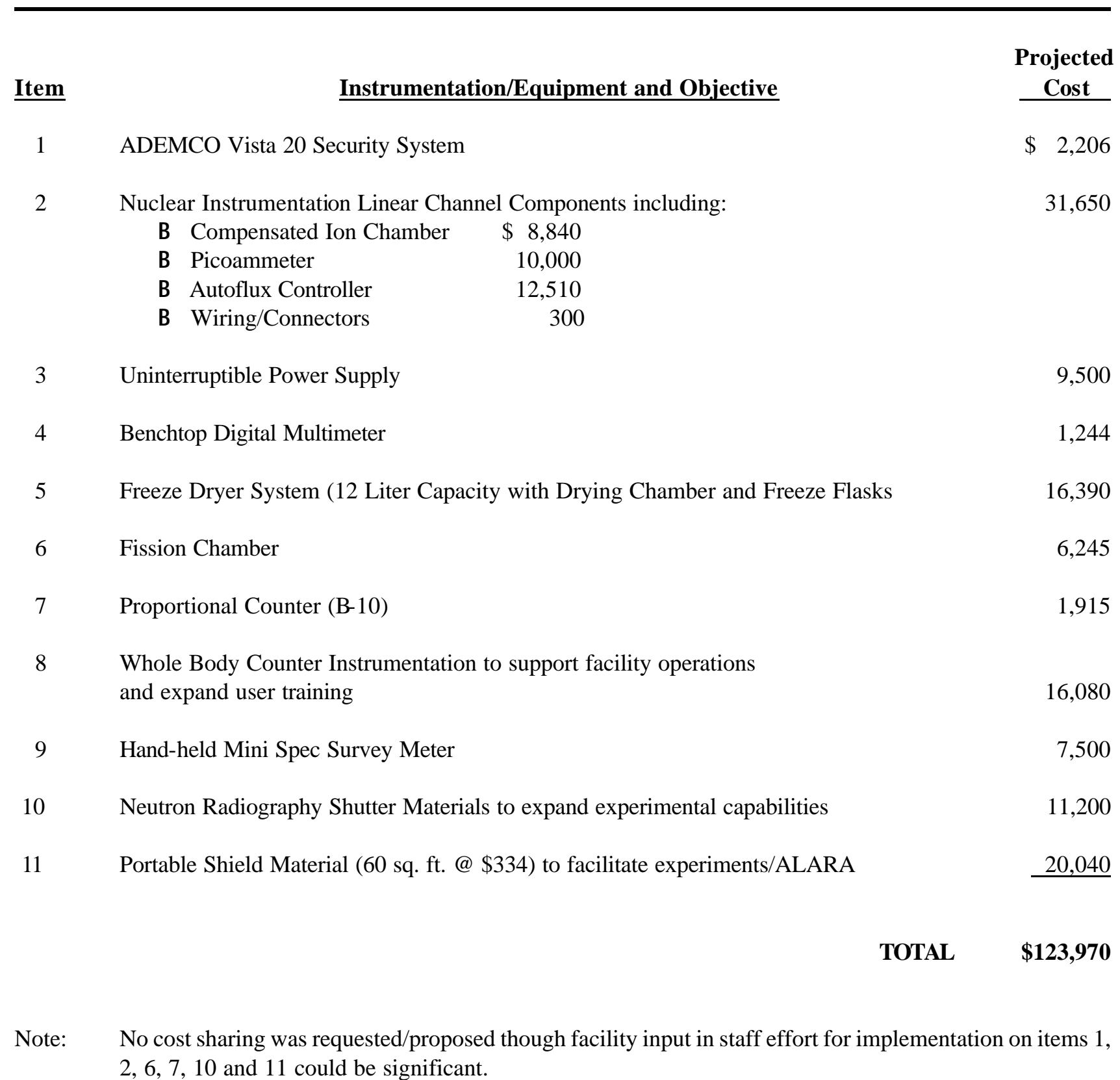


Table 2

FINANCIAL RESULTS OF UFTR 2001B2 UNIVERSITY REACTOR INSTRUMENTATION GRANT

\begin{tabular}{|c|c|c|c|c|c|}
\hline Instrumentation Item & Proposal & $\begin{array}{c}\text { Grant } \\
\text { Allocation }\end{array}$ & $\begin{array}{c}\text { Actual } \\
\text { Cost }\end{array}$ & $\begin{array}{l}\text { Charges to } \\
\text { Grant* }\end{array}$ & $\begin{array}{l}\text { Facility } \\
\text { Input*** }\end{array}$ \\
\hline $\begin{array}{l}\text { ADEMCO Vista } 20 \text { Security } \\
\text { System }\end{array}$ & $\$ 2,206$ & $\$ 2,206$ & C & C & $\sim \$ 320$ \\
\hline $\begin{array}{l}\text { Nuclear Instrumentation } \\
\text { Linear Channel Components }\end{array}$ & $\$ 31,650$ & $\$ 31,650$ & $\$ 42,940.35$ & $\$ 33,111.52$ & $\$ 9,828.83$ \\
\hline Uninterruptible Power Supply & $\$ 9,500$ & $\$ 9,500$ & $\$ 6,300.00$ & $\$ 6,300.00$ & C \\
\hline Freeze Dryer System & $\$ 16,390$ & $\$ 11,200$ & $\$ 11,824.48$ & $\$ 11,824.48$ & C \\
\hline TOTAL & $\$ 59,746$ & $\$ 54,556$ & $\$ 61,064.83$ & $\$ 51,236.00$ & $\sim \$ 10,149$ \\
\hline
\end{tabular}

\section{Unused Portion of $\$ 54,556=\$ 3,320$}

* The savings on actual cost of some grant items versus the grant allocation based on proposed costs came to $\$ 3,320$ primarily because of inability to obtain the needed security system at a cost close to that quoted. This unused cost could readily be used for personnel costs in implementing the other items as well as personnel costs in trying to plan for and order the unacquired security system.

** Though no cost sharing was requested/committed, it is estimated that facility input for unsuccessful efforts trying to acquire the security system plus the added cost for the nuclear instrumentation channel components would readily utilize the unused funds. 